\title{
A Potential Corrosion Inhibitor for Acid Corrosion of Mild Steel
}

\author{
Osarolube Eziaku \\ Department of Physics, University of Port Harcourt, Port Harcourt, Nigeria \\ Email: eziaku68@yahoo.com
}

How to cite this paper: Eziaku, O. (2017) A Potential Corrosion Inhibitor for Acid Corrosion of Mild Steel. Materials Sciences and Applications, 8, 476-483.

https://doi.org/10.4236/msa.2017.86032

Received: April 29, 2017

Accepted: June 11, 2017

Published: June 14, 2017

Copyright $\odot 2017$ by author and Scientific Research Publishing Inc.

This work is licensed under the Creative

Commons Attribution International

License (CC BY 4.0).

http://creativecommons.org/licenses/by/4.0/

\begin{abstract}
1-Phenyl-3-methylpyrazol-5-one (HPMP) was evaluated as corrosion inhibitor for mild steel in hydrochloric, nitric and perchloric acid solutions, using weight loss measurements at room temperature. HPMP was found to retard the corrosion rate of mild steel in hydrochloric and nitric acid solutions, while it aided the corrosion of same metal in perchloric acid solution. Corrosion rate decreased linearly with degree of surface coverage, and higher values of half-life were obtained for the coupons coated with HPMP inhibitor. The thicker the film of the HPMP coating on the metal, the more protection it gave to it, giving rise to the increase in inhibition efficiency.
\end{abstract}

\section{Keywords}

Corrosion, Mild Steel, Film Thickness,

1-Phenyl-3-Methylpyrazol-5-One (HPMP), Weight Loss, Surface Coverage

\section{Introduction}

Metals are the pre-eminent important materials used in structural and decorative applications. Most metals and alloys when used in different human activities are susceptible to different mechanisms of corrosion due to their exposure to different corrosive media. In petroleum industries, mild steel is regularly used in the construction of pipe lines. Many corrosion problems arise in these pipelines due to the aggressiveness of the liquids carried by them [1].

Corrosion, deterioration or destruction of metals generally, is an unavoidable but controllable process. One of the methods used to reduce the rate of metallic corrosion is the use of inhibitors [2]. Many studies have been carried out to find suitable organic and inorganic compounds to be used as corrosion inhibitors for mild steel in different aqueous solutions, for example, 1H-1,2,4-triazol-1-yl-methyl2-(4-chlorophenoxy) acetate, methocarbamol, Potassium Iodide, Pyridoxal and Pyridoxal hydrochlorides, etc. [3] [4] [5] [6] [7]. These compounds were all 
found to be good Inhibitors of mild steel. The inhibition of metal corrosion by these compounds is attributed to either the adsorption of inhibitor molecule or the formation of a layer of insoluble complex of the metal on the surface which acts as a barrier between the metal surface and the corrosive medium [8].

The present study is aimed at investigating the inhibitive properties of 1-phenyl-3-methylpyrazol-5-one on mild steel in different acid solutions such as Hydrochloric acid, Nitric and perchloric acid, using weight loss and coating methods. Parameters such as half-life and film thickness of HPMP on the metal surface will be calculated to determine the inhibition efficiency of the inhibitor.

\section{Experimental Method}

\subsection{Material Preparation}

Mild steel sheets were obtained from the Engineering workshop of University of Port Harcourt, Port Harcourt. The optical image of the as-received metal is as shown in Figure 1. The sheets were mechanically press cut into $5 \mathrm{~cm} \times 5 \mathrm{~cm}$ coupons. The two faces had $50 \mathrm{~cm}^{2}$ total geometric surface area. Each coupon was perforated with a hole at the side to allow the passage of thread for ease of handling. The metal coupons were mechanically cleaned and polished with emery paper of varying surface finish to expose clean shinning surfaces. Thereafter, the coupons were washed in distilled water to remove dirt and rust, degreased in ethanol, dipped in acetone and finally blown dry with a hand drier. The coupons were stored in a desiccator free of moisture prior to their coating with the inhibitor and their use in corrosion studies.

1-Phenyl-3-methylpyrazol-5-one (HPMP) used as inhibitor was synthesized using the method by Vogel [10]. It is insoluble in water, but soluble in a mixture

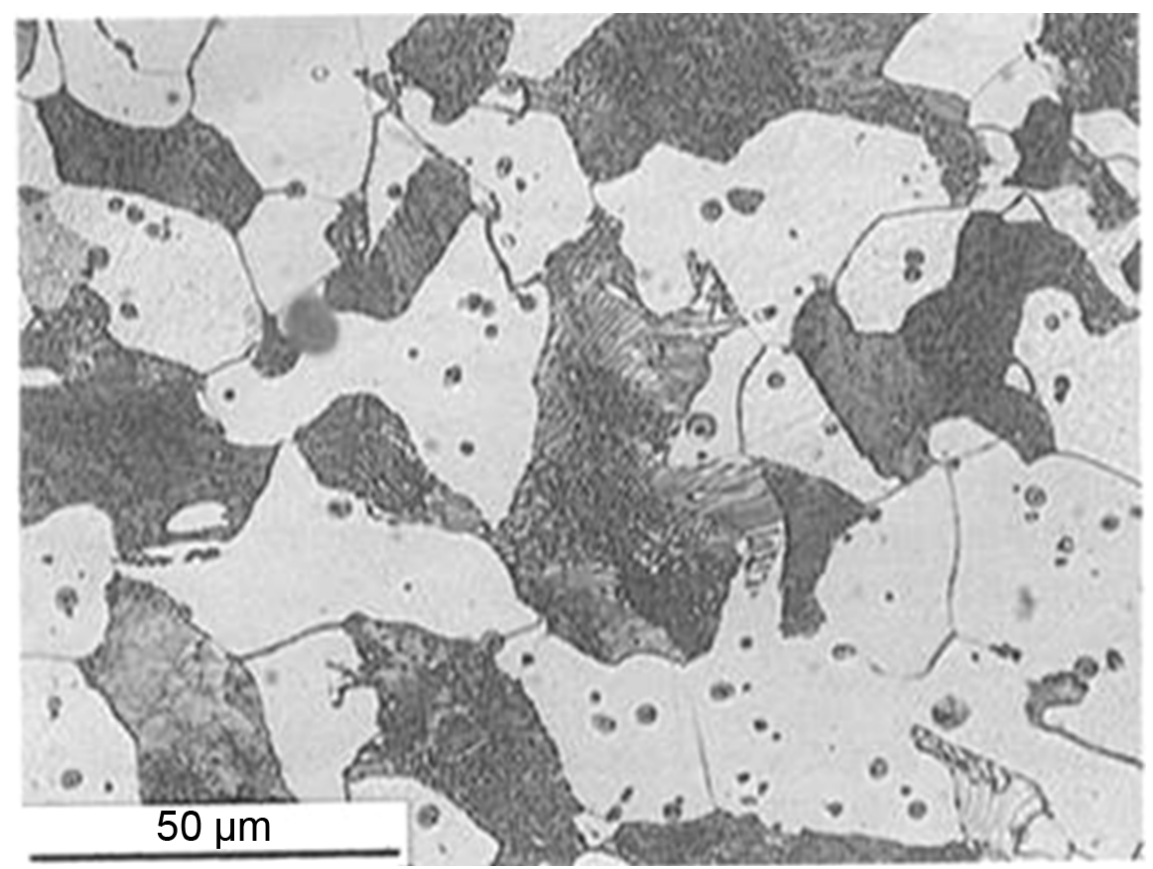

Figure 1. Microstructure of mild steel-courtesy Sun et al. [9]. 
of ethanol and water. The mild steel coupons were coated with HPMP as discussed in the previous works [11].

\subsection{Weight Loss Measurements}

Weight loss measurements were carried out as described in previous works [12] [13]. All the chemicals used were of the analytical grade. The sodium hydroxide pellets, hydrochloric acid, nitric acid, perchloric acid, ethanol and acetone, were products of May and Baker Limited, Dagenham, England. Distilled water was used for the preparation of all solutions.

\section{Experimental Results and Discussion}

\subsection{Analysis of Weight Loss Measurement Results}

The HPMP inhibitor was coated on the mild steel coupons at room temperature, and exposed to three different acidic environments. Their corresponding weight loss data are presented on Table 1. HPMP inhibited the corrosion of mild steel in $\mathrm{HCI}$ and $\mathrm{HNO}_{3}$ environments, as lower values of weight loss were recorded for the coated coupons. However, in the perchloric acid environment, the coated samples had higher values of weight loss than the uncoated samples. This signifies that the inhibitor coating on the coupons dissolved, thereby aiding the corrosion of the metal. This behavior is attributed to the fact that $\mathrm{HCIO}_{4}$ is one of the strongest acids known. It is a stronger acid than sulfuric and nitric acid. Perchloric acid is dangerously corrosive and readily forms potentially explosive mixtures [14]. It is a powerful oxidizing agent and thus causes fast dissolution of the metals.

\subsection{Corrosion Kinetics}

To characterize the corrosion reaction, the application of the principles of chemical kinetics to corrosion reaction is being explored. Calculated values of Log (W1- $\Delta \mathrm{W}$ ) obtained from the weight loss measurements were plotted against

Table 1. Weight loss (g) of coated and uncoated Mild Steel coupons in various acid solutions.

\begin{tabular}{ccccccc}
\hline \multirow{2}{*}{$\begin{array}{c}\text { Time } \\
(\text { Days })\end{array}$} & \multicolumn{5}{c}{ Weight loss $(\mathrm{g})$} \\
\cline { 2 - 7 } & \multicolumn{2}{c}{$\mathrm{HCI}$} & \multicolumn{2}{c}{$\mathrm{HNO}_{3}$} & \multicolumn{2}{c}{$\mathrm{HCIO}_{4}$} \\
\hline & $\begin{array}{c}\text { Uncoated } \\
\text { coupon }\end{array}$ & $\begin{array}{c}\text { Coated } \\
\text { coupon }\end{array}$ & $\begin{array}{c}\text { Uncoated } \\
\text { coupon }\end{array}$ & $\begin{array}{c}\text { Coated } \\
\text { coupon }\end{array}$ & $\begin{array}{c}\text { Uncoated } \\
\text { coupon }\end{array}$ & $\begin{array}{c}\text { Coated } \\
\text { coupon }\end{array}$ \\
\hline 1 & 0.3490 & 0.1346 & 2.4677 & 1.7040 & 0.2975 & 0.3067 \\
2 & 0.4573 & 0.2091 & 2.5144 & 1.7855 & 0.4853 & 0.5600 \\
3 & 0.6057 & 0.2841 & 2.7345 & 2.0199 & 0.6836 & 0.7929 \\
4 & 0.8257 & 0.4256 & 2.9570 & 2.2336 & 0.8984 & 1.0541 \\
5 & 1.0074 & 0.5360 & 3.0669 & 2.4968 & 1.0916 & 1.4532 \\
6 & 1.1764 & 0.6340 & 3.1332 & 2.7459 & 1.2454 & 1.7359 \\
7 & 1.2813 & 0.7888 & 3.1890 & 2.9865 & 1.3822 & 2.0380 \\
\hline
\end{tabular}


time as shown in Figure 2. The straight lines obtained from the plots in Figure 1 with or without inhibitor coating confirm a first order reaction kinetics with respect to mild steel in the various acidic medium. A similar result was reported earlier for the corrosion of mild steel in HCI solution [15].

The first rate equation was used to evaluate the rate constant since the dissolution of mild steel for both the uncoated and coated samples in the acid solutions obey the first order rate equation. The rate constants $(k)$ at room temperature were used to calculate the half-life $\left(t_{1 / 2}\right)$ of the system by making use of the first order reaction equation [16].

$$
t_{1 / 2}=0.693 / k
$$

where $k$ is the rate constant calculated using Equation (1).

$$
k=1 / t \ln W_{i} / W_{f}
$$

where $W_{i}$ is the initial weight of the sample, $W_{\mathrm{f}}$ is the final weight of the sample and $t$ is the immersion time (days). The calculated values of rate constants $(k)$

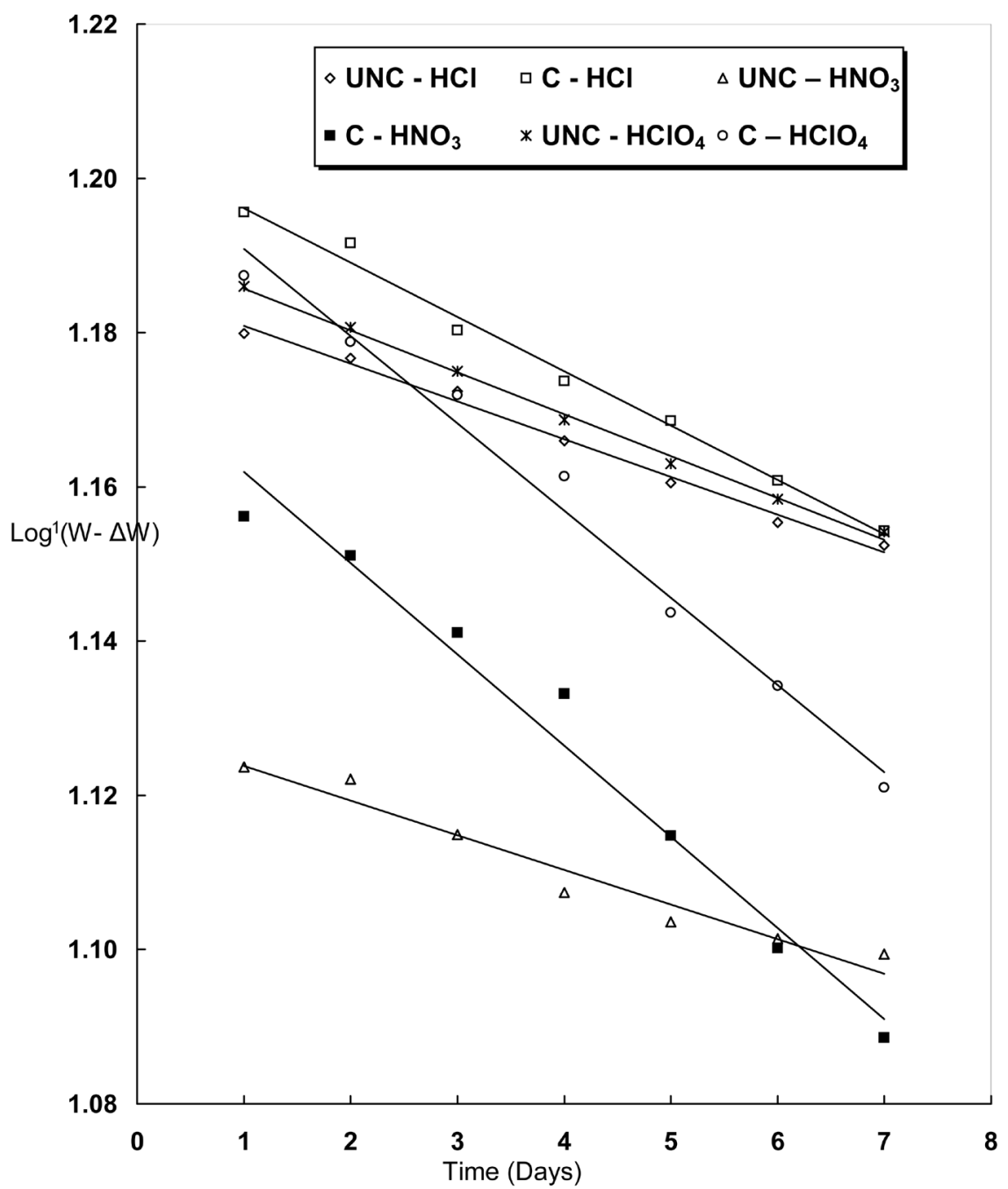

Figure 2. Variation of $\log \left(\mathrm{W}_{1}-\Delta \mathrm{W}\right)$ with time (days) for uncoated and coated mild steel in $0.5 \mathrm{~m} \mathrm{HCl}, \mathrm{HNO}_{3}$ and $\mathrm{HClO}_{4}$ solutions. 
and half-life $\left(t_{1 / 2}\right)$ obtained from Equation (1) are presented on Table 2. The results further confirm the inhibition of the metal by HPMP as higher values of half-life were obtained for the coated samples. For instance, for the uncoated mild steel coupon in HCI solution, it will take about 56.3 days for half of the coupon to decay (deteriorate) while for the coupon coated with HPMP, It will take about 113.3 days for half of the coupon to decay or corrode. This is a proof that HPMP is an effective corrosion inhibitor for mild steel. HPMP must have retarded corrosion by adsorption to form a thin invisible film only a few micrometers thick.

\subsection{Variation of Corrosion Rate with Surface Coverage}

The plot of the results of corrosion rate evaluated by Equation (3) is as shown on Figure 3.

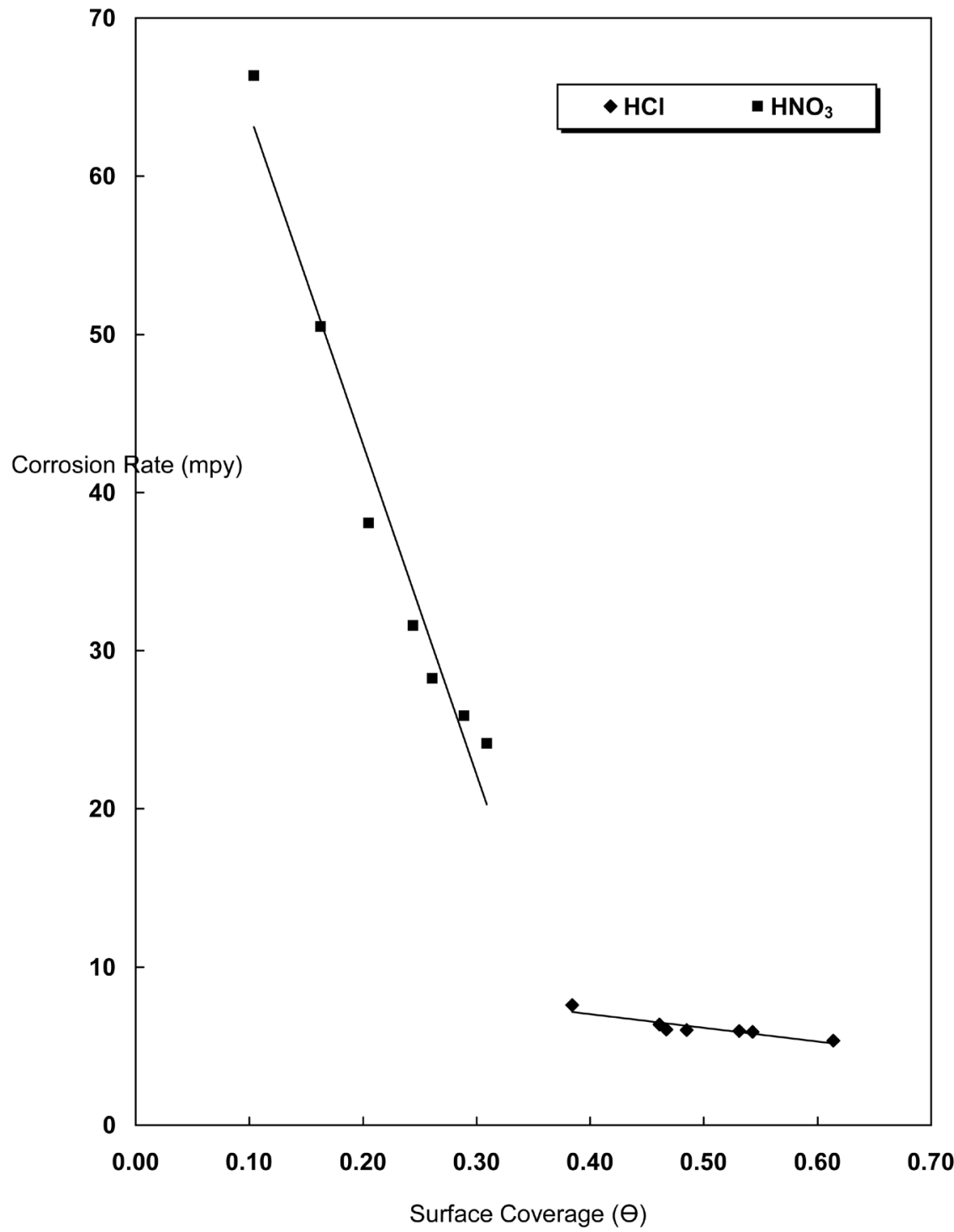

Figure 3. Variation of corrosion rates (mpy) with surface coverage $(\Theta)$ of HPMP inhibitor on mild steel in $0.5 \mathrm{~m}$ acid solution. 
Table 2. Kinetic parameters for uncoated and coated mild steel in acid solutions.

\begin{tabular}{cccc}
\hline Nature of coupon & Acid & Rate Constant $\mathrm{K}_{\left(\text {day }^{-1}\right)}$ & Half-life, $\mathrm{t}_{1 / 2}$ (days) \\
\hline Uncoated & $0.05 \mathrm{M} \mathrm{HCl}$ & 0.0123 & 56.3 \\
Coated & $0.05 \mathrm{M} \mathrm{HCl}$ & 0.0052 & 113.3 \\
Uncoated & $0.05 \mathrm{M} \mathrm{HNO}_{3}$ & 0.0323 & 21.5 \\
Coated & $0.05 \mathrm{M} \mathrm{HNO}_{3}$ & 0.0169 & 41.0 \\
Uncoated & $0.05 \mathrm{M} \mathrm{HClO}_{4}$ & 0.0133 & 52.1 \\
Coated & $0.05 \mathrm{M} \mathrm{HClO}_{4}$ & 0.0205 & 43.6 \\
\hline
\end{tabular}

$$
\text { Corrosion Rate }(\mathrm{mpy})=534 w / D A T
$$

where $w=$ weight loss (g) $D=$ density of specimen $\left(\mathrm{g} / \mathrm{cm}^{3}\right) A=$ area of specimen $\left(\mathrm{cm}^{2}\right)$ and $T$ is exposure time (hours).

It is seen from the plot that corrosion rate decreases linearly with the degree of surface coverage for the metal studied. The straight lines confirm that the inhibition is due to the adsorption of HPMP on the metal surface.

\subsection{Film Thickness ( $\mu \mathrm{m})$ and Inhibition Efficiency (\%)}

Variation of film thickness with inhibition efficiency is presented on Table 3. The result reveal that the thicker the film of the coating, the more protection it gives to the metal, giving rise to the increase in inhibition efficiency. The negative values of inhibition efficiency obtained for the metal in $\mathrm{HClO}_{4}$ environment is a further proof that there was no inhibition of the metal in perchloric acid environment. A film thickness of $13.904 \mu \mathrm{m}$ was obtained for mild steel, which yielded inhibition efficiency of $61.43 \%$. The film forms a blanket over the surface of the metal, blocking the reaction sites (surface defects), thereby protecting the metal from direct attack of the acid.

The results of Inhibition Efficiency as shown on Table 3 are evaluated using Equation (4).

$$
\text { Inhibition Efficiency }(\mathrm{IE}) \%=\left[1-W_{1} / W_{2}\right] \times 100
$$

where $W_{1}$ is weight loss of coated sample with inhibitor, and $W_{2}$ is weight loss of uncoated sample. Table 3 reveals that inhibition efficiency decreases with time in the various acidic solutions. The negative values of inhibition efficiency obtained for mild steel signify that there was no inhibition of the metal in $\mathrm{HCIO}_{4}$ solution. The results also show that the thicker the film of the coating, the more protection it gives to the metals, giving rise to inhibition efficiency. The inhibition of the corrosion process by HPMP can be attributed to adsorption of its molecules at the metal-acid solution interface. This is usually observed by the decrease in corrosion loss as measured by weight loss.

\section{Conclusions}

From the present study, it is concluded that HPMP is a potential inhibitor for 
Table 3. Film thickness ( $\mu \mathrm{m})$ and inhibition efficiency (\%) in $0.5 \mathrm{~m}$ acid concentration.

\begin{tabular}{ccccccc}
\hline \multirow{2}{*}{ Time (days) } & \multicolumn{3}{c}{ Film Thickness $(\mu \mathrm{m})$} & \multicolumn{3}{c}{ Inhibition Efficiency (\%) } \\
\cline { 2 - 7 } & $\mathrm{HCl}$ & $\mathrm{HNO}_{3}$ & $\mathrm{HClO}_{4}$ & $\mathrm{HCl}$ & $\mathrm{HNO}_{3}$ & $\mathrm{HClO}_{4}$ \\
\hline 1 & 13.904 & 12.746 & 13.209 & 61.43 & 30.95 & -3.09 \\
4 & 7.879 & 9.965 & 11.355 & 48.51 & 24.46 & -17.34 \\
7 & 6.025 & 7.647 & 6.025 & 38.44 & 6.35 & -47.45 \\
\hline
\end{tabular}

mild steel corrosion in $\mathrm{HCI}$ and $\mathrm{HNO}_{3}$ solutions. All parameters evaluated showed that there was no inhibition in $\mathrm{HCIO}_{4}$, as negative values were obtained. Higher values of half-life were obtained for the coated samples, which is a proof that HPMP inhibited the mild steel samples.

Also the thicker the film of the coating, the more protection it gives to the metals, giving rise to higher inhibition efficiency. The corrosion inhibition by HPMP can be attributed to the adsorption of its molecules at the metal surface.

\section{Acknowledgements}

I am grateful to Professor Israel Owate for his encouragement in this work and also the chemistry laboratory of the University for allowing me have access to their facilities.

\section{References}

[1] Al-Otaibi, M.S., Al-Mayouf, A.M., Khan, M., Mousa, A.A., Al-Mazroa, S.A. and Alkhathlan, H.Z. (2014) Corrosion Inhibitory Action of Some Plant Extracts on the Corrosion of Mild Steel in Acidic Media. Arabian Journal of Chemistry, 7, 340-346. https://doi.org/10.1016/j.arabjc.2012.01.015

[2] Singh, A., Ahamad, I., Singh, V.K. and Quraishi, M.A. (2011) Inhibition Effect of Environmentally Benign Karanj (Pongamia pinnata) Seed Extract on Corrosion of Mild Steel in Hydrochloric Acid Solution. Journal of Solid State Electrochemistry, 15, 1087-1097. https://doi.org/10.1007/s10008-010-1172-Z

[3] Tao, Z., Zhang, S., Li, W. and Hou, B. (2011) Adsorption and Inhibitory Mechanism of $1 H$-1,2,4-Triazol-l-yl-methyl-2-(4-chlorophenoxy) Acetate on Corrosion of Mild Steel in Acidic Solution. Industrial \& Engineering Chemistry Research, 50, 60826088. https://doi.org/10.1021/ie101793b

[4] Zerga, B., Attayibat, A., Sfaira, M., Taleb, M., Hammouti, B., Ebn Touhami, M., Radi, S. and Rais, Z. (2010) Effect of Some Tripodal Bipyrazolic Compounds on C38 Steel Corrosion in Hydrochloric Acid Solution. Journal of Applied Electrochemistry, 40, 1575. https://doi.org/10.1007/s10800-010-0164-0

[5] Attar, T., Larabi, L. and Harek, Y. (2014) The Inhibition Effect of Potassium Iodide on the Corrosion of Pure Iron in Sulphuric Acid. Advances in Chemistry, 2014, Article ID: 827514,5 pages.

[6] Gopi, D., Sherif, El-S.M., Manivannan, V., Rajeswari, D., Surendiran, M. and Kavitha, L. (2014) Corrosion and Corrosion Inhibition of Mild Steel in Groundwater at Different Temperatures by Newly Synthesized Benzotriazole and Phosphono Derivatives. Industrial and Engineering Chemistry Research, 53, 4286-4294. https://doi.org/10.1021/ie4039357

[7] Ebenso, E.E., Eddy, N.O. and Odongenyi, A.O. (2009) Inhibition of the Corrosion 
of Mild Steel by Methocarbamol. Portugaliae Electrochimica Acta, 27, 13-22. https://doi.org/10.4152/pea.200901013

[8] Okafor, P.C., Liu, C.B., Liu, X., Zheng, Y.G., Wang, F. and Liu, C.Y. (2010) Corrosion Inhibition and Adsorption Behavior of Imidazoline Salt on N80 Carbon Steel in CO2-Saturated Solutions and Its Synergism with Thiourea. Journal of Solid State Electrochemistry, 14, 1367-1376. https://doi.org/10.1007/s10008-009-0963-6

[9] Sun, Y.F., Fujii, H., Takaki, N. and Okitsu, Y. (2012) Microstructure and Mechanical Properties of Mild Steel Joints Prepared by a Flat Friction Stir Spot Welding Technique. Materials and Design, 37, 384-392. https://doi.org/10.1016/j.matdes.2012.01.027

[10] Vogel, A.I. (2002) Text Book of Practical Organic Chemistry. 4th Edition, Longman Ltd., London, 882-889.

[11] Eziaku, O. and James, A.O. (2014) Corrosion Inhibition of Mild Steel in Hydrochloric Acid by African Black Velvet Tamarind. Journal of Emerging Trend in Engineering and Applied Sciences, 5, 51-55.

[12] Eziaku, O. (2014) Effect of an Organic Inhibitor on the Electrical Properties of High Carbon Steel in Simulated Acid Environment. Journal of Materials Science and Chemical Engineering, 2, 28-33.

[13] Eziaku, O., Owate, I.O. and Oforka, N.C. (2008) Corrosion Behaviour of Mild and High Carbon Steels in Various Acidic Media. Scientific Research and Essay, 3, 224228. http://www.academicjournals.org/SRE

[14] Mendiratta, S.K., Dotson, D.L. and Brooker, R.T. (2005) Perchloric Acid and Perchlorates. Kirk-Othmer Encyclopedia of Chemical Technology.

[15] James, A.O., Oforka, N.C., Abiola, O.K. and Ita, B.I. (2007) A Study on the Inhibition of Mild Steel Corrosion in Hydrochloric Acid by Pyridoxol Hydrochloride. Electica Quimica, 32, 31-36. https://doi.org/10.1590/s0100-46702007000300005

[16] Atkins, P.W. (1980) Chemisorbed and Physisorbed Species: A Textbook of Physical Chemistry. University Press, Oxford, 936-938.

Submit or recommend next manuscript to SCIRP and we will provide best service for you:

Accepting pre-submission inquiries through Email, Facebook, LinkedIn, Twitter, etc. A wide selection of journals (inclusive of 9 subjects, more than 200 journals) Providing 24-hour high-quality service User-friendly online submission system Fair and swift peer-review system Efficient typesetting and proofreading procedure

Display of the result of downloads and visits, as well as the number of cited articles Maximum dissemination of your research work

Submit your manuscript at: http://papersubmission.scirp.org/

Or contact msa@scirp.org 